Published in final edited form as:

J Res Educ Eff. 2015 ; 8(1): 84-111. doi:10.1080/19345747.2014.972601.

\title{
Disentangling Disadvantage: Can We Distinguish Good Teaching from Classroom Composition?
}

\author{
Gema Zamarro, \\ University of Arkansas, University of Southern California Dornsife Center for Economic and Social \\ Research \& RAND Corporation, 219-B Graduate Education building, Department of Education \\ Reform, University of Arkansas, Fayetteville, AR 72701 (gzamarro@uark.edu) \\ John Engberg, \\ RAND Corporation, 4570 Fifth Avenue, Suite 600 Pittsburgh, PA 15213-2665, \\ (engberg@rand.org) \\ Juan Esteban Saavedra, and \\ University of Southern California Dornsife Center for Economic and Social Research, University \\ of Southern California, 635 Downey Way, Los Angeles, CA 90089-3332 (juansaav@usc.edu) \\ Jennifer Steele \\ American University, 215 Gray Hall, 4400 Massachusetts Ave., NW, Washington, DC \\ 20016-8030 (steele@american.edu)
}

\section{Abstract}

This paper investigates the use of teacher value-added estimates to assess the distribution of effective teaching across students of varying socioeconomic disadvantage in the presence of classroom composition effects. We examine, via simulations, how accurately commonly-used teacher-value added estimators recover the rank correlation between true and estimated teacher effects and a parameter representing the distribution of effective teaching. We consider various scenarios of teacher assignment, within-teacher variability in classroom composition, importance of classroom composition effects, and presence of student unobserved heterogeneity. No single model recovers without bias estimates of the distribution parameter in all the scenarios we consider. Models that rank teacher effectiveness most accurately do not necessarily recover distribution parameter estimates with less bias. Since true teacher sorting in real data is seldom known, we recommend that analysts incorporate contextual information into their decisions about model choice and we offer some guidance on how to do so.

\section{Introduction}

Unequal access to effective teaching in public schools is a longstanding policy concern. Evidence that low-income and minority students are disproportionately taught by novice and academically weak teachers has guided a number of policy initiatives aimed at improving these students' performance. These initiatives include not only the "highly qualified teacher" 
provisions of No Child Left Behind, but also the Teacher Incentive Fund grants and the teacher-effectiveness provisions in the Race to the Top grants. More recently, a 2014 Los Angeles Superior Court ruling that overturned teacher tenure statutes in California was informed by evidence that poor and minority students are taught by teachers with weaker observable characteristics (Vergara v. State of California, 2014).

These efforts, including the recent court ruling, have responded to evidence about the distribution of teacher characteristics-features like years of experience, licensure status, licensure test scores, or college competitiveness. This body of research has shown that students who are low-income or minority, or who attend low-performing schools, are disproportionately taught by teachers who are inexperienced, unlicensed, or have weak academic backgrounds (Betts, Rueben, \& Danenberg, 2000; Clotfelter, Ladd, \& Vigdor, 2005; Clotfelter, Ladd, Vigdor, \& Wheeler, 2007; Guarino, Brown \& Wyse, 2011; Lankford, Loeb, \& Wyckoff, 2002; Loeb \& Reininger, 2004).

However, research demonstrates clearly that these characteristics are only weakly related to teachers' impact on student learning, as measured by teachers' value-added to students' performance on standardized tests (Aaronson, Barrow, \& Sander, 2007; Kane \& Staiger, 2005; Rivkin, Hanushek, \& Kain, 2005; Rockoff, 2004). Teacher value-added is usually understood as the contribution of a teacher to the learning of his/her students as measured by test scores and conditional on other factors, including students' background and preparation. Teachers are considered to be effective if their students make above average improvements relative to other teachers with comparable students (see, for example, Buddin \& Zamarro, 2009; Hannaway et al., 2010).

The extent to which low-income and minority students are taught by less effective teachers - that is, by teachers with below-average value-added-is not as clear. Studies that have addressed this question have generally shown lower effectiveness among teachers in highpoverty schools relative to other schools, but in most studies, the differences have been quite small, have varied by district, and have shown greater variation within than between schools (Sass, Hannaway, Xu, Figlio, \& Feng, 2012; Mansfield, 2010; Glazerman \& Max, 2011). In contrast, an ongoing study of three districts and one charter management organization recently found that disadvantaged students enjoyed slightly greater access to effective teachers in many cases, and that sorting within schools was less-favorable to disadvantaged students than sorting between schools (Steele et al., 2014). Meanwhile, a recent study of 29 districts also demonstrated small differences in teacher effectiveness favoring moreadvantaged students, though patterns again varied among districts, and sorting appeared greater between than within schools (Isenberg et al., 2013). What is clear from these studies is that there is no overarching consensus in the literature about how teacher effectiveness is distributed, despite its distribution being an important concern for policymakers.

Measuring disadvantaged students' access to effective teachers requires examining the relationship between teachers' value-added estimates and the characteristics of the students they teach. This process is complicated by the fact that value-added estimates are intended to disentangle teachers' contributions from other contributions to student learning, family and neighborhood factors, for which race and socioeconomic variables often serve as proxies. 
Since important legislative and judicial decisions have hinged on evidence about students' access to effective teachers, it is important not only to measure teacher effectiveness accurately, but also to accurately measure the relationship between effectiveness and student characteristics. As a motivating example, we show that in data from a large urban U.S. school district, conclusions about the distribution of effective teachers with respect to student disadvantage are different depending on the model we use to estimate teacher effects.

In this paper, we use simulated data generated under a variety of assumptions to examine how well a variety of common value-added modeling approaches accurately capture teachers' relative contributions to learning and also how well they allow us to capture disadvantaged students' access to effective teaching.

While attempts have been made at quantifying the bias of different teacher value-added models to measure teacher effectiveness using simulation methods (for example, Rothstein, 2009; Guarino, Reckase, and Wooldridge, 2013), we are not aware of papers that attempt to quantify bias in estimates of a distribution parameter that measures the correlation between teacher effectiveness and students' socioeconomic background in the presence of classroom composition effects. This paper aims to address this issue.

To understand the suitability of various teacher value-added models for estimating the relationship between teacher effectiveness and students' socioeconomic characteristics, we employ a simulation approach in which we vary our model specifications, as well as our assumptions about teacher assignment, within-teacher variability in classroom composition, importance of classroom composition effects, presence of student unobserved heterogeneity and choice of controls in the value-added specification.

We examine how accurately commonly used value-added modeling approaches are able to recover the (a) true teacher effects, as measured by the rank correlation between true and estimated teacher effects and (b) the correlation between teacher effects and demographic characteristics of their students ${ }^{1}$. We examine these parameters-which, henceforth refer to as the rank correlation and the distribution parameter-in models estimated with and without controls for classroom-level demographic characteristics. We fit models using four distinct value-added specifications explained in greater detail below: aggregated residuals, teacher random effects, teacher fixed effects (with post-hoc Empirical Bayes shrinkage) and, in simulations with unobserved student heterogeneity, teacher and student fixed effects models.

Specifically, we test these models under scenarios of random assignment of teachers to students, and systematic assignment such that disadvantaged students are taught by less-

\footnotetext{
${ }^{1}$ Although alternative parameters could be used for measuring the performance of estimators recovering teacher effects and degree of systematic teacher assignment with respect to student disadvantage, we focus on the rank correlation to assess the performance of teacher value added models in recovering true teacher effects to relate better to other papers in the literature that use simulation methods to investigate how well teacher value added models recover true teacher effects (e.g. Guarino, Reckase, and Wooldridge, 2013). Similarly, we use correlation coefficients between estimated teacher effects and the teachers' aggregate proportion of student disadvantage as our distribution parameter estimate as these are the most natural way to model teacher assignment with classroom effects in our simulation setup, described later, thereby allowing us to intuitively quantify bias.
} 
effective teachers. We also examine the models under scenarios of high and low classroom composition effects, high and low variability in average classroom demographics among the classes taught by a single teacher, and with and without student unobserved heterogeneity.

To make the simulations tractable, we make some simplifying assumptions. First, among the possible array of student characteristics that could potentially generate classroom composition effects, we consider the percent of students with observed background disadvantage (OBD) in a class as the only form of peer effect in the model.

The focus on percent OBD students in a class, however, captures an essential feature of policies aimed at modifying school or classroom composition: the focus on race and income. A longstanding question in education policy has been whether school integration generates peer effects. For example, the Boston's Metropolitan Council for Educational Opportunity (METCO) is a desegregation program that sends students to more affluent suburbs. Busing programs such as METCO typically send African American students to schools that were previously majority white (Angrist and Lang, 2004). In Charlotte-Mecklenburg, as recently as 2001, it was prohibited to use race in assigning students to schools (Billings, Deming and Rockoff, forthcoming). Similarly, the Wake County school district each year reassigns numerous students to balance schools' racial or income composition and these reassignments generate variation in classroom peer effects (Hoxby and Weingarth, 2006).

Second, in scenarios in which we incorporate student unobserved heterogeneity, we model such time-invariant heterogeneity as a function only of student socioeconomic disadvantage. Finally, we also assume that there is no measurement error in test scores.

In all scenarios we consider, we find that no single model recovers estimates of the distribution parameter without bias. Moreover, models that rank teachers according to their effectiveness most accurately do not necessarily recover distribution parameter estimates with less bias.

Since true teacher sorting in real data is seldom known, we recommend that analysts incorporate contextual information into their decisions about model choice and we offer some guidance on how to do so. Specifically we propose two diagnostic tests: i) a comparison of overall variability of teacher- and school-effect estimates in the real data (Buddin and Zamarro, 2009); and ii) a variance decomposition of student socioeconomic disadvantage in its between-classroom and within-classroom overtime components. These two tests can shed light on the degree of sorting of effective teachers across schools and on the variation in classroom composition that is available to disentangle good teaching from classroom composition.

The rest of the paper is organized as follows. Section 2 empirically motivates our simulation approach with data from a large, urban district, in which we find that estimates of our parameters of interest are sensitive to modeling decisions. Section 3 describes assumptions about the education production function, and Section 4 presents the data-generating process for the simulations. Section 5 describes the modeling specifications we choose and their rationales. Section 6 presents results for each scenario and modeling choice. Section 7 concludes with a discussion of implications for analyses with real-world data. 


\section{The Sensitivity of Estimates of the Distribution of Effective Teaching with Respect to Student Disadvantage}

We motivate the use of simulations with empirical estimates of a distribution parameter that is the correlation between estimated teacher effects and a teachers' aggregate proportion of OBD students in a sample of achievement data from elementary school children in grades 2 through 5 from a large urban U.S. school district for eight consecutive school years. The data also contains student level information on race/ethnicity, eligibility for subsidized meals, as well as classroom and teacher identifiers.

Estimation of the distribution parameter proceeds in two steps. For models estimated in testscore levels, in the first step we estimate a student-level regression in which the dependent variable is students' reading test scores as a function of students' one-year lagged reading test scores, students' OBD status (which takes the value of one if the student is minority and eligible for subsidized meals) and, in some models, the class proportion of OBD students, which is intended to separate classroom composition effects from individual teacher effects.

2 For models estimated in test-score gains, the dependent variable in the student-level regression is the one-year test score gain and the independent variables are students' OBD status and, in some models, the class proportion OBD.

In the second step, we estimate the correlation coefficient between teacher effect estimates and aggregate socioeconomic disadvantage of all the students ever assigned to that teacher. ${ }^{3}$ Table 1 shows estimates of the distribution parameter for various teacher value added models.

Empirical estimates of the distribution parameter are sensitive to modeling approach, as well as to whether we control or not for the classroom proportion OBD. For example, when we estimate teacher effect models in levels, we obtain negative distribution parameters, leading us to conclude that more effective teachers tend to be assigned to classrooms with fewer proportions of OBD students. Results from fixed and random teacher effects models in levels, however, suggests more unequal access to effective teachers by disadvantaged students than would otherwise suggest aggregated residuals teacher effects models. Similarly, when we estimate models in test-score gains, we would be inclined to conclude that students from all backgrounds are equally likely to have access to an effective teacher and, if anything, more so for socioeconomically disadvantaged students. Notice also that whether we control or not for classroom composition by including class proportion OBD as an explanatory variable changes our conclusions about the distribution of effective teaching in some instances.

This example illustrates the empirical challenge of assessing how unequal the access to effective teaching is among public-school students. Without any prior knowledge of how

\footnotetext{
${ }^{2}$ Test-scores are standardized to have a mean of 0 and a standard deviation of 1 in each year. Similar results were obtained when using student's math test scores instead of reading test scores. The results for math are available from the author's upon request.

${ }^{3}$ For teacher fixed effects models we include an intermediate step in which we "shrink" teacher effect estimates from step one to account for heterogeneity in the amount of information available to estimate each teacher's contribution to student achievement (Jacob \& Lefgren, 2007)
} 
teachers are sorted across schools and how they are assigned to classrooms within schools, it is difficult to substantiate the use of one value added model over other. Moreover, as we will show later, models that do a good job of recovering teacher effects are not necessarily those best suited to estimate the distribution parameter with the least amount of bias.

One diagnostic approach to shed light on the extent to which, in real data applications, there is a systematic relationship between teacher effectiveness and student disadvantage is to compare the overall standard deviation of empirical estimates of teacher effects with the overall standard deviation of school effects, when school effects are included in the model instead of teacher effects (Buddin and Zamarro, 2009). The intuition is as follows. If all effective teachers are concentrated in a few good schools with low proportions of socioeconomically disadvantaged students-and thus teacher assignment is systemic with respect to student characteristics, at least across schools - the standard deviation of teacher effects and the standard deviation of school effects should be of comparable magnitudes: it is equivalent to be in a good school as it is to be assigned to an effective teacher.

Alternatively, if teacher assignment across schools is not systematic, effective teachers are to be found in schools with different composition of student body, the standard deviations of teacher effects and school effects would differ.

In the data used in Table 1, the standard deviation of estimated teacher effects is 0.293 and the standard deviation of estimated school effects is 0.097 . This suggests that there is not much teacher sorting across schools with varying socioeconomic disadvantage composition.

The second diagnostic test is to investigate the amount of variation in student disadvantage between and within classrooms over time. Appendix B describes in detail this variance decomposition approach and results in our empirical example data. In brief, we find that most of the variation in student disadvantage is across classrooms: there is little variation within classrooms over time in the proportion of disadvantaged students. As a result, valueadded models that only use the within variation to identify teacher effects, such as teacher fixed effects, could have a hard time disentangling good teaching from classroom composition in this setting.

To summarize, in our motivating empirical example there appears to be little sorting of effective teaching across schools and limited variability in classroom composition overtime. In our simulation scenarios described below we will consider such situation as well as others.

\section{Education Production Function}

This section describes the theoretical model that underlies our Monte Carlo simulation approach. Denote $T_{i t}$ as the test score measure of student $i$ that is observed in year $t$, and let $X_{i t}$ and $\xi_{i t}$ represent observed and unobserved inputs for student $i$ at time $t$, respectively. Let $\mu_{\mathrm{i} 0}$ be the student's time-invariant endowed ability. The cognitive production function is linear in inputs and unobserved endowments. Input effects do not depend on the student's age but may depend on the age at which they were applied relative to the current age (Todd and Wolpin, 2003). Under these assumptions, an education production function can be written as: 


$$
T_{i t}=\mu_{i 0}+\alpha_{1} X_{i t}+\alpha_{2} X_{i t-1}+\ldots+\delta_{1} \xi_{i t}+\delta_{2} \xi_{i t-1}+\ldots+\omega_{i t}
$$

The equation for lagged test score $T_{i t-1}$ is:

$$
T_{i t-1}=\mu_{i 0}+\alpha_{1} X_{i t-1}+\alpha_{2} X_{i t-2}+\ldots+\delta_{1} \xi_{i t-1}+\delta_{2} \xi_{i t-2}+\ldots+\omega_{i t-1}
$$

Multiplying the lagged test score equation by $\beta$, the persistence rate of prior learning (where persistence is defined as one minus decay), we get:

$$
\beta T_{i t-1}=\beta \mu_{i 0}+\beta \alpha_{1} X_{i t-1}+\beta \alpha_{2} X_{i t-2}+\ldots+\beta \delta_{1} \xi_{i t-1}+\beta \delta_{2} \xi_{i t-2}+\ldots+\beta \omega_{i t-1}
$$

Subtracting equations (1) and (2) yields:

$T_{i t}-\beta T_{i t-1}=(1-\beta) \mu_{i 0}+\alpha_{1} X_{i t}+\left(\alpha_{2}-\beta \alpha_{1}\right) X_{i t-1}+\ldots+\delta_{1} \xi_{i t}+\left(\delta_{2}-\beta \delta_{1}\right) \xi_{i t-1}+\ldots+\left(\omega_{i t}-\beta \omega_{i t-1}\right)$

Assuming constant decay (i.e. $a_{t}=\beta a_{t-1}$ and $\delta_{t}=\beta \delta_{t-1}, \forall t$ ), equation (3) becomes:

$$
T_{i t}-\beta T_{i t-1}=(1-\beta) \mu_{i 0}+\alpha_{1} X_{i t}+\delta_{1} \xi_{i t}+\left(\omega_{i t}-\beta \omega_{i t-1}\right)
$$

Adding $\beta T_{i t-1}$ to both sides of the equation we obtain that:

$$
T_{i t}=(1-\beta) \mu_{i 0}+\alpha_{1} X_{i t}+\beta T_{i t-1}+\delta_{1} \xi_{i t}+\left(\omega_{i t}-\beta \omega_{i t-1}\right)
$$

For simplicity, we further assume that the only observed student input is OBD status, which is time-invariant. Since we can link each student to a specific teacher and classroom assignment, we can represent the effect of the teacher and classroom composition by a timevarying classroom effect, $\gamma_{j t}$ Therefore, we can operationalize equation (4) with the following two equations:

$$
\begin{gathered}
T_{i t}=(1-\beta) \mu_{\mathrm{i} 0}+\alpha^{\prime} O B D_{i}+\beta T_{i t-1}+\gamma_{j t}+v_{i t} \\
\gamma_{j t}=\lambda \overline{O B D}_{j t}+\phi_{j}+\varepsilon_{j t}
\end{gathered}
$$

Classroom effects are the sum of the three components: a time-varying peer effect component captured by the class proportion of OBD students $\left(\overline{O B D}_{j t}\right)$ in a given year, a time-invariant teacher effect, $\varphi_{j}$, and a random error term, $\varepsilon_{j t}$, which represents other unmeasured attributes of classroom $j$ at time $t$ that contribute to the performance of student $i$.

Equations (5) and (6) constitute the basis of our data-generating process. As described in the next section, we generate data under empirically guided assumptions about parameters $a, \lambda$ and $\beta$. We vary the assignment of teachers to classrooms to create various degrees of correlation between a teacher's time-invariant effectiveness, $\varphi_{j}$, and the average characteristics of her students over all of her classes, $\overline{O B D}_{j}$. We refer to this correlation as 
$\rho$, (i.e.
simulations. $\left.^{\rho=} \frac{\operatorname{Cov}\left(\phi_{j}, \overline{O B D}_{j}\right)}{\sigma_{\phi_{j}} \cdot \sigma_{\overline{O B D}_{j}}}\right)$ and it is our main parameter of interest in the Monte Carlo

\section{Data-Generating Process for Simulations}

To make the problem tractable, we make some simplifying choices in our Monte Carlo simulations. We only consider socioeconomic disadvantage and use the teacher value-added estimates to assess the distribution of effective teaching across students of varying socioeconomic disadvantage. As noted above, the focus on percent OBD students in a class, however, captures an essential feature of policies aimed at modifying school or classroom composition: the focus on race and income.

Second, in scenarios in which we incorporate student unobserved heterogeneity, we model such time-invariant heterogeneity as a function only of student socioeconomic disadvantage. Finally, we also assume that there is no measurement error in test scores.

Our Monte Carlo simulations use 100 samples of data that we generate from equations (5) and (6). We assume a single cohort of 2,400 students that we observe for four consecutive years. Half of the students in the simulated data are assigned OBD status, and students are assigned into schools randomly, so that the distribution of the school-average number of disadvantaged students has a mean of 0.5 and standard deviation $0.3 .{ }^{4}$ There are 120 teachers total so that average classroom size is twenty students per teacher, although in the simulations, class size varies randomly, with a minimum of ten students per teacher. ${ }^{5}$

Time-invariant teacher effects $\left(\varphi_{j}\right)$ are drawn from a normal distribution with mean zero and standard deviation 0.2. Similarly, $\varepsilon_{j t}$ in equation (6) above is also a draw from a normal distribution with mean zero and standard deviation 0.1. With these assumptions, we derive time-varying classroom effects from equation (6). ${ }^{6}$

Baseline student test scores are generated following a standard normal distribution, $T_{i 0}$ $N(0,1)$, that is independent of student's OBD status. For each subsequent year, student test scores are generated following equation (5) above, assuming $v_{i t}$ is normally distributed with mean and standard deviation such that the resulting test scores have mean zero and variance 1 in each period. ${ }^{7}$

Our simulation set up is similar to that of Guarino, Reckase, and Wooldridge (2013). Like them, we omit measurement error or school effects in our data generating process. We also ignore student mobility across schools. An important difference with their work, however, is that in our simulations, we vary classroom composition and allow for peer effects to affect student outcomes each year. They assume there are no peer effects in their simulations.

\footnotetext{
${ }^{4}$ This distribution replicates the distribution of school-average OBD observed in administrative data from a large, urban school district.

${ }^{5}$ A detailed description of our simulations set up can be found in Appendix C.

${ }^{6}$ The standard deviation of this error distribution is restricted so that the resulting variance of the error in the test score equation $v_{i t}$ has feasible values.

${ }^{7}$ Baseline scores are, therefore, not correlated with students' OBD status, but subsequent scores are.
} 
We consider various scenarios of teacher assignment, within-teacher variability in classroom composition, importance of classroom composition effects, presence of student unobserved heterogeneity and choice of control variables in the value added specification. We now describe how we modify conditions for each.

\section{Teacher assignment}

We consider two teacher assignment scenarios: random assignment $(\rho \approx 0)$ and partially systematic assignment based on the proportion of OBD students in the classroom in which the most effective teachers tend to be assigned to classrooms with the lowest proportions of OBD students $(\rho \approx-0.5)$. Note that the latter represents a considerably more systematic teacher assignment case that what we estimated exists in our motivating example of Section 2. We focus on this rather extreme case in addition to random assignment to provide insight on the models' performance under a broad range of conditions.

\section{Within-teacher variability in classroom composition}

We consider two scenarios of student and teacher mobility. Our first scenario is one of extreme variability in classroom composition. In this case, we ignore the school dimension, and students and teachers are re-assigned into classrooms each year. This scenario corresponds to a case in which we have similar amounts of between- and within-teacher variation in classroom composition.

Our second scenario limits the variability in classroom composition over time, generating a scenario that would more closely mimic situations in which schools are located in certain types of neighborhoods, students remain in the same school for subsequent years, and teachers serve similar types of students year after year. This case results in a larger proportion of between-teacher variation in proportion of students in the classroom with OBD status than in the case of high mobility. For the limited mobility scenario we consider 20 schools with 6 teachers per school. Teachers and students are assigned into schools the first year and not allowed to leave the school in subsequent years. Students are then reassigned to classrooms each year within schools. ${ }^{8}$

\section{Importance of classroom composition effects}

We consider two scenarios for the importance of classroom composition effects that are a function of the classroom proportion OBD. In the student-level regression that produces teacher effect estimates for Table 1, the coefficient estimate for the classroom proportion OBD is $\lambda=-0.03$, which is our assumption for the scenario of small classroom composition effects. For our scenario of large classroom composition effects we assume $\lambda=-0.3$, which is the coefficient estimate for the classroom proportion OBD in a student-level regression like the one used for Table 1 in data from a different urban school district.

\footnotetext{
${ }^{8}$ Note that our data-generating process does not include school effects that are separate from the combined effects of teacher, classroom, and student characteristics. Disentangling teacher and school effects reliably requires that numerous teachers are observed for multiple years before and after changing schools. Though these conditions would be straightforward to generate within simulated data, they would have limited applicability to many analytic situations, where separating school and teacher effects requires large panel datasets and several assumptions about the stability of teacher effects across contexts (see, for instance, Jackson, 2012; Mansfield 2010; and Xu et al., 2012). For tractability of the current analysis, we focus just on distinguishing teacher from classroom composition effects.
} 
We set $\beta=0.8 ; \alpha=-0.08$ in all situations, which are the coefficient estimates in the value added models used to produce results in Table $1 .{ }^{9}$ These two parameter choices suggest, respectively, high learning persistence and a weak negative correlation between studentlevel OBD and student scores. ${ }^{10}$

\section{Presence of student unobserved heterogeneity}

In our main simulations there is no unobserved student heterogeneity in the data-generating process. However, as a sensitivity analysis, we also consider a scenario with unobserved heterogeneity that is a function of student's OBD status. ${ }^{11} \mathrm{We}$ only study unobserved heterogeneity for the case of limited variability in classroom composition as this turns out to be the most interesting scenario leading to greater differences in performance across estimated models.

\section{Choice of classroom composition controls}

We consider two scenarios for classroom composition controls. In some models we control for the classroom average proportion OBD and in other models we omit this classroom average control. ${ }^{12}$

Because our distribution parameter of interest is the correlation between time-invariant teacher's value-added estimates and the fraction of OBD students a given teacher has, we are also concerned about disentangling the effects of classroom composition from the effects of teacher effectiveness. If all teachers were observed teaching only one course, or if each course a teacher taught had an equal share of OBD students, then it would be impossible to separate teacher and classroom composition effects. However, insofar as teachers are assigned to classes that vary in the proportion of OBD, it may be possible to disentangle class composition from time-invariant teacher effects. Still, because our ability to disentangle the two types of effects likely depends on the amount of variation in the compositions of classes taught by the same teacher over time, we fit models that do and do

\footnotetext{
${ }^{9}$ It is difficult to compare these parameter estimates from teacher value added models with those from prior studies for two reasons. First, many prior studies of teacher value added do not report parameter estimates from student-level regressions. Second, among those that report parameter estimates, it is often the case that either: a) the set of student-, classroom- and teacher-level covariates included in the regression is more comprehensive than ours (e.g. Clotfelter et al. 2007), or b) include student fixed effects that absorb time-invariant student characteristics (e.g. Rockoff 2004; Clotfelter et al. 2010; Hannaway et al. 2010). Having said that, available parameter estimates are quantitatively similar to the ones we employ in our simulations. For example, using student achievement data for grades 3-5 from North Carolina and a much richer specification, Clotfelter et al. (2007) report estimates of $\beta$ of around 0.7 and of $\lambda$ of around -0.1. Similarly, using high school achievement data from North Carolina, Clotfelter et al. (2010) report estimates of a of -0.06 and of $\beta$ of around 0.4 .

${ }^{10}$ We also performed simulation exercises varying the persistence parameter $\beta$ to smaller values ( 0.4 and 0.2$)$, with similar conclusions. Model performance in recovering true teacher effects decreases at lower levels of persistence. No such clear pattern emerges, however, in the distribution parameter. Results for these lower persistence cases are available from the authors upon request. We do not consider other scenarios for the choice of $a$ as we are primarily concerned with features of the data-generating process that we believe are potentially most relevant for the problem we study.

${ }^{11}$ Specifically, we expand equation (5) and allow for an additional student unobserved heterogeneity term drawn from a standard uniform distribution such as there is a negative correlation with student's OBD status. The average correlation between student unobserved heterogeneity and OBD status in our simulated data is -0.6 approximately. Although we acknowledge that this is a rather high correlation and this scenario might represent an extreme case where a big part of the unobserved heterogeneity will be controlled by observed student disadvantage background, we still think the presented results are informative.

${ }^{12} \mathrm{We}$ could have also considered models in which we control for other classroom composition variables such as classroom average test-scores. We do not do so for two reasons. First, doing so would increase considerably the number of scenarios we consider. Second, classroom average lagged test-scores are correlated with classroom proportion OBD but do not enter the data-generating process directly. Situations in which we control for classroom average lagged scores are, therefore, an intermediate case from those in which we control and do not control for the classroom proportion OBD.
} 
not include controls for classroom composition. Because, the aggregated residual model assumes that covariates such as classroom proportion OBD are orthogonal to teacher effects - an assumption violated in the presence of teacher sorting - the question of whether and when to adjust for classroom composition in value-added models remains an important analytic consideration.

In total, we consider sixteen simulation scenarios for the case of no student unobserved heterogeneity ( 2 scenarios of teacher assignment $\times 2$ scenarios of mobility $\times 2$ scenarios of classroom composition effects $\times 2$ scenarios of classroom controls). For the case of student unobserved heterogeneity we consider eight possible scenarios ( 2 scenarios of teacher assignment $\times 1$ scenario of mobility $\times 2$ scenarios of classroom composition effects $\times 2$ scenarios of classroom controls), for a total of twenty-four scenarios to test how well the various teacher value-added models we describe in the next section recover the distribution of effective teaching with respect to student disadvantage in the presence of classroom composition effects.

\section{Modeling Specifications Tested}

We arrive at our basic estimating equation by substituting equation (6) into (5) above to obtain:

$$
T_{i j t}=\alpha_{0}+\alpha_{1} T_{i t-1}+\alpha_{2} O B D_{i}+\alpha_{3} \overline{O B D}_{j t}+\eta_{i j t}
$$

where $\eta_{\mathrm{ijt}}=\varphi_{j}+\varepsilon_{\mathrm{jt}}+v_{\mathrm{it}}$.

For the simulation scenarios without unobserved student heterogeneity, we estimate three teacher value-added models: i) aggregated residuals (e.g., Kane and Staiger, 2008; Chetty, Friedman and Rockoff, forthcoming); ii) teacher random effects (e.g., McCaffrey et al., 2003); and iii) teacher fixed effects (e.g., Rothstein, 2010) with Empirical Bayes adjustment ${ }^{13}$. For each type of model, we fit equations in levels by regressing the current score on explanatory variables that include the lagged score. ${ }^{14}$

In the aggregated residuals model, we estimate equation (7) by OLS and compute residuals $\left(\eta_{\mathrm{ijt}}\right)$. We then obtain Empirical Bayes teacher-effect estimates, $\hat{\varphi_{\mathrm{j}}}$, by applying a random effects estimation in the following equation:

$$
\hat{\eta}_{\mathrm{ijt}}=\phi_{j}+\zeta_{\mathrm{ijt}}
$$

Aggregating the residuals to estimate teachers' effectiveness assumes, by construction, that teachers' time-invariant effects $\left(\varphi_{\mathrm{j}}\right)$ are not correlated with other explanatory variables in the

\footnotetext{
${ }^{13}$ We also obtained estimates using teacher fixed effects methods without Empirical Bayes adjustments and results were similar to the adjusted ones presented here.

${ }^{14}$ We also fitted equations in gains by omitting the lagged test score from the set of explanatory variables and using gains in test scores as our dependent variable instead. In general, models in gains did worse than models in levels in recovering the size of teacher contributions to student outcomes. When estimating the degree of sorting, models in levels also did better than models in gains in the presence of sorting of teachers into certain classrooms. However, in the absence of student sorting, models in gains perform better at recovering the distribution parameter. Results are available from the authors upon request.
} 
model. Any true variance in teacher effectiveness associated with classroom-average characteristics may be attributed to the classroom-average covariates, potentially leading to biased estimates of teacher value-added. This is a key potential drawback of this type of model for estimating the correlation between teacher value-added and student characteristics, though the severity of the bias under varying assumptions is an empirical question.

Teacher random effects or variance-components models assume that a portion of the unexplained variation in students' test scores is associated with teacher effectiveness. The random effects model differs from the aggregated residuals model in that the presence of the teacher random effect in the error term places greater weight on the within-teacher relationship between test scores and covariates, and this weight increases with the number of within-teacher observations in the data. In such a model, the teacher value added is estimated by the best linear unbiased prediction, which reflects the imprecision in each teacher's estimate due to the number of students taught and the correlation with classroom covariates (McCaffrey et al., 2003). Like aggregated residuals, teacher random effects estimates of equation (7) are obtained under the additional assumption that the teacher timeinvariant effects are not correlated with the rest of explanatory variables in the model. Random effects estimators give us teacher effects that are already shrunken, and no further Empirical Bayes adjustments are necessary. As both aggregated residuals methods and teacher random effects estimates require that explanatory variables are not correlated with the teacher time-invariant effects, they will provide biased estimates when we deviate from the random assignment of teachers into classrooms. It is an empirical question, however, how this bias in the estimated coefficients translates into bias in the estimation of our correlation parameter of interest, $\rho$.

Teacher fixed effects models are estimated by allowing teacher time invariant effects $\left(\varphi_{j}\right)$ to be correlated with observed student and classroom characteristics. These models are, therefore, robust to non-random assignment of teachers into classrooms based on observable student characteristics. With small samples and limited variability of classroom composition, however, teacher fixed effect models can suffer from noisily estimated parameters for both classroom composition and teacher effects. This is so because they only use variation within teachers over time to distinguish between the effects of classroom composition and teacher effectiveness. ${ }^{15}$

\footnotetext{
${ }^{15}$ There is another potential source of bias in the fixed effects estimator if teachers have some of the same students in consecutive years. It is well known that panel data models that include both student fixed effects and a lagged dependent variable lead to biased estimates (Nickell, 1981). Although our specifications use teacher fixed effects and not student fixed effects, a similar bias will occur in our levels specification if some students have the same teacher in consecutive years. For these "repeater" students, their lagged test score will be correlated with the true teacher effect for their current year, a part of which will be in the error term for the estimated model. This could lead to bias in all the estimated coefficients in the equation if the time varying unobserved classroom shocks $\left(\zeta_{i j t}\right)$ are correlated over time. This correlation could be accentuated in practice if classroom composition does not vary sufficiently over time. In our limited classroom variability scenario in which students and teachers stay in the same school, one-sixth of the students on average have the same teacher in consecutive years. However, by construction we do not allow the unobserved classroom shocks to be correlated over time and so, we do not expect this source of bias to be important for our simulation results. It should be stressed, however, that in actual data available to us from several large, urban districts, up to 15 percent of students were taught by the same teacher in consecutive years. Having the same teacher can happen for multiple reasons including being held back or limited availability of teachers in smaller districts.
} 
For the teacher fixed effects models, we apply Empirical Bayes adjustments to our teacher effects estimates following Tate (2004). Let $\hat{\sigma}_{j}^{2}$ be the estimated variance of the teacher effect estimate $\varphi_{\mathrm{j}}$ and $\mu$ and $\sigma^{\hat{2}}$ be the mean and variance, respectively, of the distribution of estimated teacher effects in the sample. We construct the Empirical Bayes estimate of each teacher's value-added as:

$$
\phi_{\mathrm{j}}^{\mathrm{EB}}=\hat{\phi}_{\mathrm{j}} \cdot \chi_{\mathrm{j}}+\bar{\mu} \cdot\left(1-\chi_{\mathrm{j}}\right)
$$

where $\chi_{\mathrm{j}}$ is the reliability of $\hat{\varphi_{\mathrm{j}}}$, which equals $\hat{\sigma}^{2} /\left(\hat{\sigma}^{2}+\hat{\sigma}_{\mathrm{j}}^{2}\right)$.

For the simulation scenarios with unobserved student heterogeneity we also estimate models that include student fixed effects along with teacher fixed effects. In value-added models with student fixed effects, teacher effects are identified off variation in teacher effectiveness for a given student. Such variation might arise, for example, across subjects (e.g. Clotfelter et al., 2010) or, as is our case here, over time as different teachers teach the same student in different school years (e.g. Rothstein, 2010). To avoid the bias that arises from the inclusion of student fixed effects and lagged test scores (Nickell, 1981), models with student and teacher fixed effects are typically estimated using gain scores as dependent variable and omitting lagged test scores in the set of explanatory variables (e.g. Rivkin et al., 2005; Clotfelter et al. 2010; Hannaway et al. 2010).

Once we estimate the various value-added models described above, in a second step we estimate the correlation coefficient between teacher effect estimates and aggregate proportion OBD among all the students ever assigned to that teacher. In each simulation replication we compute confidence intervals of the estimated distribution correlation coefficient by using Fisher z-transformations. As a summary statistic for the level of uncertainty with which we estimate the distribution parameter in each simulation scenario, we report exact p-values for the null hypothesis of the correlation coefficient being zero, which are number of simulation replications in which the Fisher z-transform confidence interval includes zero, divided by 100 , the total number of data replications.

\section{Results}

We present results for scenarios without unobserved student heterogeneity in subsections 6.1 and 6.2. Subsection 6.1 discusses results when teacher assignment is random. Subsection 6.2 presents results with partially systematic teacher assignment with respect to student disadvantage. Subsection 6.3 discusses results for simulation scenarios with unobserved student heterogeneity.

\subsection{Random teacher assignment without unobserved student heterogeneity}

We highlight two findings about the accuracy of estimated teacher effects in recovering true teacher contributions to learning in cases with random teacher assignment in which models control for classroom proportion OBD (Panel A of Table 2). First, for all modeling choices and assumptions about the importance of classroom composition effects, teacher value added estimates more accurately recover true teacher effects in scenarios with extreme 
variability in classroom composition over time than in those with limited variability, as measured by the rank correlation between true and estimated effects. This is particularly true for teacher fixed effects models, which is not surprising since teacher fixed effects models only use within-teacher variation to identify teacher effects.

Second, particularly for the case of limited variability in classroom composition over time, the accuracy of estimated teacher effects generally diminishes as the importance of classroom composition effects increases. Note that both teacher random and fixed effects models perform very similarly in terms of their ability to rank teachers, even when teacher assignment is partially systematic. Part of the reason is that we are simulating estimates with three years of achievement data (plus a baseline lagged score). With multiple years of data, random effects estimates would converge to the fixed effects estimates. ${ }^{16}$

Turning to estimates of the distribution parameter, regardless of assumptions about the importance of classroom composition effects, under extreme variability in classroom composition, all models generally produce unbiased estimates of the distribution parameter. Based on the p-values for the null hypothesis of the distribution correlation being zero, aggregated residuals models, however, are the most unbiased followed by teacher random effects and lastly teacher fixed effects (Panel A of Table 2).

With limited variability in classroom composition, random- and fixed-effects models produce biased estimates of the distribution correlation, suggesting that in such situations, it is empirically difficult to separate classroom composition effects from teacher effectiveness. For example estimates of the distribution parameter from teacher fixed effects models in levels are negatively biased when there is limited variability in classroom composition. The estimated average distribution correlation is -0.023 when classroom composition effects are small and -0.23 with large classroom composition effects (columns 3 and 6, Panel A of Table 2).

A possible explanation for the bias in the distribution correlation from teacher fixed effect models is that coefficient estimates in the student level regression-particularly that for the classroom proportion OBD variable-are more biased in the teacher fixed effect model than in aggregated residuals and random teacher effect models in scenarios with limited variability in classroom composition (see Appendix Table A1). This problem is more severe when true classroom composition effects are large. ${ }^{17}$

Not controlling for classroom composition does not affect our main conclusions about the accuracy of teacher effect estimates under random teacher assignment and the various

\footnotetext{
${ }^{16}$ In other analyses (results not shown, available upon request) we have also estimated rank and distribution correlations with only one year of achievement data (plus a baseline score). In those simulations, the rank correlation of true and estimated teacher random effects more closely resembles the rank correlation of true and estimated teacher effects from the aggregated residuals model than that from the fixed effects models. Similarly, when using less data, estimates of the distribution correlation from random effects models resemble those from aggregated residuals models. The result that with minimum years of achievement data random effects and aggregated residuals models perform similarly in terms of their ability to rank teachers is consistent with simulation results in Guarino, Reckase and Wooldridge (2013). However, unlike Guarino, Reckase and Wooldridge (2013), we find that with minimum data, fixed effects estimates always appear to rank teachers more accurately than estimates from aggregated residuals or random effects models. We hypothesize that this divergence stems from the fact that in our simulations, we consider peer effects in the data generating process, unlike theirs.
} 
scenarios we consider (Panel B of Table 2). Not doing so, however substantially affects our conclusions about the distribution of effective teachers with respect to student disadvantage. Specifically, we highlight two substantive changes.

First, regardless of modeling choice and assumptions about the importance of classroom composition effects, not controlling for classroom composition leads to more biased estimates of the distribution correlation even in the case of extreme variability in classroom composition. Second, as Panel B of Table 2 shows, not controlling for classroom composition introduces considerable bias in estimates of $\rho$ derived from aggregated residuals and teacher random effects methods, particularly in the case of limited variability in classroom composition. Before, estimates of $\rho$ from aggregated residuals models were centered around zero, whereas now the distribution parameter mean is $\rho=-0.18$ for the case of large classroom composition effects. The direct contribution of classroom composition to student learning — which previously was controlled for-now loads onto the estimated teacher effects, creating an spurious correlation with a teacher's proportion of disadvantaged students. Since in our simulations teacher quality positively affects learning while the classroom proportion of disadvantaged students negatively does so, the direction of the bias becomes negative.

\subsection{Partially systematic teacher assignment without unobserved student heterogeneity}

Introducing systematic teacher assignment does not fundamentally alter our conclusion that teacher effect estimates from settings with extreme variability in classroom composition are more accurate at recovering true teacher effects than those from settings with limited variability in classroom composition (Panel A, Table 3). However, we now find that the accuracy of estimated teacher effects increases slightly in most cases as the relevance of classroom composition effects increases.

Systematic teacher assignment also fundamentally alters our conclusions about the appropriateness of various value-added models to recover the distribution of teacher effectiveness with respect to student background disadvantage. For example, as Table 3, Panel A, indicates, in the case of extreme variability in classroom composition, all modelsparticularly aggregate residuals - understate the degree of teacher sorting with respect to student disadvantage.

Second, unlike the case of random teacher assignment, teacher fixed effects models produce the best estimates of the distribution correlation, followed by random effects and lastly aggregated residuals. When classroom composition effects are large, fixed effects models do a better job at recovering the true distribution correlation than when they are small, but even in the case of small classroom composition effects, teacher fixed effects performs notably

\footnotetext{
${ }^{17}$ Even if teacher assignment is random, the covariance between contemporaneous classroom proportion of student disadvantage and lagged classroom average scores is non-zero. With limited variability in classroom composition, a teacher gets assigned to a similar "type" of student year-after-year so that there is systematic correlation between classroom composition, teacher effectiveness and student learning over time. Limited variability in classroom composition is, therefore, not a concern in aggregated residuals models because by assuming that teacher effects are the portion of test scores that are uncorrelated with covariates included in the model, aggregated residuals is effectively imposing orthogonality between teacher value-added and classroom composition.
} 
better than aggregated residuals and teacher random effects specially when there is limited variability in classroom composition.

As Appendix Table A2 shows, part of the reason aggregated residuals models perform so poorly at recovering the distribution correlation is that, when teacher assignment is partially systematic, aggregated residuals models overstate the true contribution of classroom composition to student learning. In doing so, the aggregated residuals model is purging some of the true contribution of teacher effectiveness to learning, and because teacher effectiveness positively affects student learning, the resulting estimate of the distribution correlation is biased towards zero. Although this coefficient was also biased in the case of random assignment the bias was not as severe as with partially systematic teacher assignment.

Finally, Panel B of Table 3 presents results on the accuracy of teacher effect estimates and of the distribution correlation parameter $\rho$ when there is systematic teacher assignment and we exclude controls for classroom composition. Results for the case of extreme variability in classroom composition are comparable to those that control for classroom proportion OBD. The main difference, however, arises in the case of limited variability in classroom composition for the aggregated residuals model.

When there is limited variability in classroom composition and we do not control for the classroom proportion of disadvantaged students, the accuracy of teacher effect estimates from all methods increases considerably (Panel B of Table 3). This improvement in accuracy is most pronounced for aggregate residuals methods.

Not controlling for classroom composition improves estimates of $\rho$ using aggregated residuals in cases with limited variability in classroom composition. For example, when classroom composition effects are large the average estimated $\rho$ is now -0.39 which is much closer to the true value of -0.5 (when controlling for classroom composition our estimated $\rho$ was only -0.06). Not controlling for classroom composition also improves estimates of $\rho$ using teacher random effects models. Estimates of $\rho$ from teacher random effects methods resemble those of teacher fixed effects models without the classroom control (Column 2, Panel B of Table 3).

Aggregated residuals and random effects models assume, respectively, that all or a portion of the unexplained variation in students' test scores is associated with teacher effectiveness. The random effects model places greater weight on the within-teacher relationship between test scores and covariates, and this weight increases with the number of within-teacher observations in the data. For this reason, in situations with limited variability in classroom composition over time, the omission of classroom composition controls in the student-level equation improves the performance of aggregated residuals and random effects in recovering distribution parameter estimates. 


\subsection{Random and partially systematic teacher assignment with student unobserved heterogeneity}

We now discuss results of simulations in which student unobserved heterogeneity is part of the data generating process. Tables 4 and 5 present the results for the cases of random assignment of teachers into classrooms and student systematic sorting, respectively, when there is limited variability in classroom composition. In addition to results from the three value added models discussed in previous simulation scenarios, we also present estimates of models in test-score gains that include both teacher and student fixed effects.

Comparing the results of Tables 4 and 5 with those in Tables 2 and 3 we observe that the introduction of student unobserved heterogeneity reduces significantly the accuracy of estimated teacher effects and better resemble the values for rank correlations presented by Guarino, Reckase, and Wooldridge, 2013. Concerning the teacher distribution parameter aggregated residuals continues to be the method leading to the best estimates in the case of random assignment, followed in this case by models that include both student and teacher fixed effects. Under partially systematic sorting of teachers into classrooms, however, all models produce estimates of the distributional parameter $\rho$ that are considerably biased.

\section{Conclusion and discussion}

It is unclear the extent to which low-income and minority students are taught by less effective teachers. Empirical estimates of a parameter describing the distribution of teacher effectiveness in real data yield markedly different conclusions depending on which teacher value added model is employed.

To shed light on this question we explore, via simulations, how various teacher value-added models recover estimates of a parameter that captures the distribution of effective teaching across students of varying socioeconomic disadvantage. A key element in our simulations is the presence of classroom composition effects as student performance is assumed to depend on own as well as on classroom average disadvantage.

None of the teacher value added models we discuss is capable of recovering without bias the distribution parameter of effective teaching with respect to student disadvantage in all of the simulation scenarios we consider. Moreover, value added models that do well at recovering true teacher contributions to learning are not necessarily those that do a good job on estimating the distribution of effective teaching with respect to student disadvantage. Teacher fixed effects models typically recover the distribution parameter with less bias than other valued added approaches when teacher assignment to classrooms is based on student characteristics. When teacher assignment is random, however, aggregated residuals methods perform better at recovering the distribution parameter. In the presence of unobserved student heterogeneity and partially systematic teacher assignment, no model recovered without bias estimates of the distribution parameter, illustrating how challenging it may be in some settings to determine the extent to which poor and minority students in public schools have unequal access to effective teaching. 
Given the sensitivity of distribution parameter estimates to assumptions about teacher assignment, within-teacher variability in classroom composition, the importance of classroom composition effects and student unobserved heterogeneity, we propose that empirical analyses that aim to assess the distribution of effective teaching with respect to student characteristics guide their modeling choice with additional contextual analyses.

One diagnostic approach to shed light on the extent to which, in real data applications, there is a systematic relationship between teacher effectiveness and student disadvantage is to compare the standard deviation of empirical estimates from models that include teacher effects versus the standard deviation from models that estimated school effects instead (Buddin and Zamarro, 2009). The second diagnostic test is to investigate the amount of variation in student disadvantage between and within classrooms over time.

In data from a large urban school district that we use as motivating example we find little evidence of systematic teacher assignment to schools with higher proportions of disadvantaged students and limited variation in classroom composition over time. Based on our simulation results, aggregated residuals models with classroom composition controls are potentially the most accurate in recovering distribution parameter estimates in such a setting, even in the presence of unobserved student heterogeneity. This prediction is, however, context-specific, underscoring our prescription for a careful contextual analysis to guide modeling choice.

\section{Acknowledgements}

The authors thank Erik Meijer, Jonah Rockoff, James Wyckoff, Manuel Arellano, Brian Stecher, and seminar participants at AEFP $37^{\text {th }}$ Annual Conference, IES funded Conference "Using Student Test Scores to Measure Teacher Performance: The State of the Art in Research and Practice", Centro de Estudios Monetarios y Financieros (CEMFI) and the Department of Education Reform at the University of Arkansas for helpful comments and suggestions. We also wish to thank the Bill \& Melinda Gates Foundation and the USC Dornsife Center for Economic and Social Research, which provided funding for this research. Juan Saavedra also acknowledges financial support from the National Institute of Ageing, RCMAR grant P30AG043073. Finally, we are also very grateful for the comments received from Cassandra Guarino and two anonymous referees. The opinions expressed here are solely those of the authors and do not represent those of the project sponsors, the RAND Corporation, the University of Southern California or any of its sponsors. Any errors are the responsibility of the authors.

\section{References}

Aaronson D, Barrow L, Sander W. Teachers and student achievement in the Chicago Public High Schools. Journal of Labor Economics. 2007; 25:95-135.

Angrist J, Lang K. Does School Integration Generate Peer Effects? Evidence from Boston's Metco Program. American Economic Review. 2004; 94(5)

Betts, JR.; Rueben, KS.; Danenberg, A. Equal resources, equal outcomes: The distribution of school resources and student achievement in California. Vol. 2008. San Francisco: Public Policy Institute of California; 2000.

Buddin R, Zamarro G. Teacher qualifications and student achievement in urban elementary schools. Journal of Urban Economics. 2009; 66:103-115.

Chetty R, Friedman JN, Rockoff JE. Evaluating bias in value-added estimates. American Economic Review. (Forthcoming).

Clotfelter CT, Ladd HF, Vigdor JL. Who teaches whom? Race and the distribution of novice teachers. Economics of Education Review. 2005; 24(4):377-392. 
Clotfelter, CT.; Ladd, HF.; Vigdor, JL.; Wheeler, J. High poverty schools and the distribution of teachers and principals. Washington, DC: National Center for the Analysis of Longitudinal Data in Education Research; 2007.

Clotfelter CT, Ladd HF, Vigdor JL. Teacher credentials and student achievement in high school: A cross-subject analysis with student fixed effects. Journal of Human Resources. 2010; 45(3):655681.

Deming D, Billings S, Rockoff J. School Resegregation, Educational Attainment and Crime: Evidence from the End of Busing in Charlotte-Mecklenburg. Quarterly Journal of Economics. (Forthcoming).

Glazerman, S.; Max, J. Do low-income students have equal access to the highest-performing teachers?. Washington, DC: National Center for Education Evaluation and Regional Assistance, Institute of Education Sciences, U.S. Department of Education; 2011.

Guarino C, Brown A, Wyse A. Can districts keep good teachers in the schools that need them most? Economics of Education Review. 2011; 30(5):962-975.

Guarino, C.; Reckase, MD.; Wooldridge, JM. Can value-added measures of teacher performance be trusted?. Bloomington, IN: Indiana University; 2013.

Hannaway, J.; Xu, Z.; Sass, TR.; Figlio, D.; Feng, L. Value added of teachers in high-poverty schools and lower poverty schools: Implications for research, policy and management; Paper presented at the Association of Public Policy Analysis and Management Fall Conference; Boston, MA. 2010 Oct 19.

Hoxby, C.; Weingarth, G. Taking Race out of the Equation: School Reassignment and the Structure of Peer Effects. Mimeo: Stanford University; 2006.

Isenberg, E.; Max, J.; Gleason, P.; Potamites, L.; Santillano, R.; Hock, H.; Hansen, M. Access to effective teaching for disadvantaged students. Washington, DC: National Center for Education Evaluation and Regional Assistance, Institute of Education Sciences, U.S. Department of Education; 2013.

Jackson CK. Match quality, worker productivity, and worker mobility: Direct evidence from teachers. The Review of Economics and Statistics. 2012

Jacob BA, Lefgren L. Principals as agents: Subjective performance assessment in education. Journal of Labor Economics. 2007; 26(1):101-136.

Kane, TJ.; Staiger, DO. Using imperfect information to identify effective teachers. Cambridge, MA: National Bureau of Economic Research; 2005. p. 61

Kane, TJ.; Staiger, DO. Working paper no. 14607. Cambridge, MA: National Bureau of Economic Research; 2008. Estimating teacher impacts on student achievement: An experimental evaluation.

Lankford H, Loeb S, Wyckoff J. Teacher sorting and the plight of urban schools: A descriptive analysis. Educational Evaluation and Policy Analysis. 2002; 24(1):37-62.

Loeb, S.; Reininger, M. Public policy and teacher labor markets: What we know and why it matters. East Lansing, MI: The Education Policy Center at Michigan State University; 2004. p. 1-64.

Mansfield, RK. Unpublished manuscript. New Haven, CT: Yale University; 2010. Teacher quality and student inequality.

McCaffrey, DF.; Lockwood, JR.; Koretz, DM.; Hamilton, LS. Evaluating value-added models for teacher accountability. Santa Monica, CA: RAND Corporation; 2003. p. 191

Nickell S. Biases in Dynamic Models with Fixed Effects. Econometrica. 1981; 49(6):1417-1426.

Rivkin SG, Hanushek EA, Kain JF. Teachers, schools, and academic achievement. Econometrica. 2005; 73(2):417-458.

Rockoff JE. The impact of individual teachers on student achievement: Evidence from panel data. American Economic Review. 2004; 94(2):247-252.

Rothstein J. Student sorting and bias in value-added estimation: Selection on observables and unobservables. Education Finance and Policy. 2009; 4(4):537-571.

Rothstein J. Teacher quality in educational production: Tracking, decay and student achievement. Quarterly Journal of Economics. 2010; 125(1):175-214.

Sass, TR.; Hannaway, J.; Xu, Z.; Figlio, D.; Feng, L. Value added of teachers in high-poverty schools and lower poverty schools. Washington, DC: National Center for Analysis of Longitudinal Data in Education Research; 2012. 
Steele, JL.; Baird, M.; Engberg, J.; Hunter, G. WR-1036-BMGF. Santa Monica, CA: RAND

Corporation; 2014. Trends in the distribution of teacher effectiveness in the Intensive Partnerships for Effective Teaching.

Tate R. A cautionary note on shrinkage estimates of school and teacher effects. Florida Journal of Educational Research. 2004; 42:1-21.

Todd PE, Wolpin KI. On the specification and estimation of the production function for cognitive achievement. The Economic Journal. 2003; 113(485):F3-F33.

Vergara v. State of California, No. BC484642, County of Los Angeles. Superior Court of the State of California. 2014

$\mathrm{Xu}, \mathrm{Z}$; Ozek, U.; Corritore, M. Portability of teacher effectiveness across school settings. Washington, DC: National Center for the Analysis of Longitudinal Data in Education Research; 2012.

\section{Appendix}

\section{Appendix Table A1}

Monte Carlo simulation value added model parameter estimates under random teacher assignment (i.e. $\rho=0$ ). The true value for the coefficient on OBD status $(\alpha)$ is -0.08 ; for the coefficient on class proportion $\operatorname{OBD}(\lambda)$ is -0.03 for the case of small classroom composition effects and -0.3 for the case of large classroom composition effects.

\begin{tabular}{|c|c|c|c|c|c|c|c|}
\hline & & \multicolumn{3}{|c|}{ Small Classroom Composition Effects } & \multicolumn{3}{|c|}{ Large Classroom Composition Effects } \\
\hline & & $\mathbf{A R}$ & $\mathbf{R E}$ & $\mathbf{F E}$ & $\mathbf{A R}$ & $\mathbf{R E}$ & $\mathbf{F E}$ \\
\hline \multirow{2}{*}{$\begin{array}{l}\text { Variability in Classroom } \\
\text { Composition }\end{array}$} & & \multicolumn{6}{|c|}{ Panel A. Controlling for classroom composition } \\
\hline & $\hat{\beta}$ & 0.324 & 0.324 & 0.324 & 0.329 & 0.328 & 0.328 \\
\hline Extreme & $\hat{a}$ & -0.147 & -0.147 & -0.147 & -0.137 & -0.138 & -0.138 \\
\hline \multirow{6}{*}{ Limited } & $\lambda^{\wedge}$ & -0.110 & -0.097 & -0.096 & -0.717 & -0.719 & -0.719 \\
\hline & $\hat{\beta}$ & 0.352 & 0.333 & 0.332 & 0.364 & 0.341 & 0.339 \\
\hline & $a^{\hat{a}}$ & -0.143 & -0.145 & -0.145 & -0.141 & -0.145 & -0.145 \\
\hline & $\lambda \hat{~}$ & -0.029 & -0.005 & 0.013 & -0.459 & -0.221 & -0.028 \\
\hline & & \multicolumn{6}{|c|}{ Panel B. Not controlling for classroom composition } \\
\hline & $\hat{\beta}$ & 0.324 & 0.324 & 0.324 & 0.329 & 0.328 & 0.328 \\
\hline Extreme & $\hat{a}$ & -0.152 & -0.150 & -0.150 & -0.173 & -0.163 & -0.162 \\
\hline \multirow{2}{*}{ Limited } & $\hat{\beta}$ & 0.352 & 0.333 & 0.332 & 0.375 & 0.342 & 0.339 \\
\hline & $\hat{a}$ & -0.151 & -0.145 & -0.145 & -0.274 & -0.156 & -0.146 \\
\hline
\end{tabular}

Notes: This table shows average estimates from 100 Monte Carlo simulations with four years of student test score data, 120 teachers a single cohort of 2,400 students and data generating process following the parameterization described in the text. $\mathrm{AR}=$ aggregated residuals model; $\mathrm{RE}=$ teacher random effects model; $\mathrm{FE}=$ teacher fixed effects model; EB-FE=empirical Bayes teacher fixed effects model. In the extreme variability of classroom composition scenario we assume that there is only one school and all teachers and students are randomly reassigned to classrooms each year. In the limited variability of classroom composition scenario we assume that there are 20 schools, no student or teacher mobility across schools and teachers and students are reassigned randomly to classrooms each year within school. 


\section{Appendix Table A2}

Monte Carlo simulation value added model parameter estimates under partially systematic teacher assignment of the most effective teachers to low-proportion OBD classrooms (i.e. $\rho=$ $-0.5)$ controlling for classroom average OBD. The true value for the coefficient on OBD status (a) is -0.08 ; for the coefficient on class proportion $\operatorname{OBD}(\lambda)$ is -0.03 for the case of small classroom composition effects and -0.3 for the case of large classroom composition effects.

\begin{tabular}{|c|c|c|c|c|c|c|c|}
\hline & & \multicolumn{3}{|c|}{ Small Classroom Composition Effects } & \multicolumn{3}{|c|}{ Large Classroom Composition Effects } \\
\hline & & $\mathbf{A R}$ & $\mathbf{R E}$ & $\mathbf{F E}$ & $\mathbf{A R}$ & $\mathbf{R E}$ & $\mathbf{F E}$ \\
\hline \multirow{2}{*}{$\begin{array}{l}\text { Variability in Classroom } \\
\text { Composition }\end{array}$} & & \multicolumn{6}{|c|}{ Panel A. Controlling for classroom composition } \\
\hline & $\hat{\beta}$ & 0.328 & 0.328 & 0.328 & 0.329 & 0.328 & 0.328 \\
\hline \multirow[t]{3}{*}{ Extreme } & $a^{\hat{n}}$ & -0.130 & -0.130 & -0.130 & -0.137 & -0.138 & -0.138 \\
\hline & $\lambda^{\hat{\gamma}}$ & -1.069 & -0.172 & -0.081 & -0.717 & -0.719 & -0.719 \\
\hline & $\hat{\beta}$ & 0.363 & 0.343 & 0.341 & 0.364 & 0.341 & 0.339 \\
\hline \multirow[t]{4}{*}{ Limited } & $a^{\hat{n}}$ & -0.140 & -0.142 & -0.143 & -0.141 & -0.145 & -0.145 \\
\hline & $\lambda \hat{}$ & -0.568 & -0.279 & -0.04 & -0.955 & -0.467 & -0.021 \\
\hline & & \multicolumn{6}{|c|}{ Panel B. Not controlling for classroom composition } \\
\hline & $\hat{\beta}$ & 0.328 & 0.328 & 0.328 & 0.329 & 0.327 & 0.327 \\
\hline Extreme & $\hat{a}$ & -0.182 & -0.135 & -0.132 & -0.178 & -0.136 & -0.133 \\
\hline \multirow{2}{*}{ Limited } & $\hat{\beta}$ & 0.378 & 0.344 & 0.341 & 0.421 & 0.359 & 0.353 \\
\hline & $a^{\hat{\imath}}$ & -0.296 & -0.157 & -0.143 & -0.406 & -0.167 & -0.144 \\
\hline
\end{tabular}

Notes: Table shows average estimates from 100 Monte Carlo simulations with four years of student test score data, 120 teachers a single cohort of 2,400 students and data generating process following the parameterization described in the text. $\mathrm{AR}=$ aggregated residuals estimation model; $\mathrm{RE}=$ random effects estimation model; $\mathrm{FE}=$ fixed effects estimation model. In extreme variability of classroom composition scenario we assume that there is only one school and all teachers and students are randomly reassigned to classrooms each year. In limited variability of classroom composition scenario we assume that there are twenty schools, no student mobility across schools and teachers and students are reassigned randomly each year within school.

\section{Appendix Table B1}

Variability of proportion OBD in classrooms

\begin{tabular}{lr}
\hline & Std. Deviation \\
\hline Overall & 0.308 \\
Between & 0.263 \\
Within & 0.177 \\
\hline
\end{tabular}


Appendix Table B2

Details of variability of proportion OBD in classrooms

\begin{tabular}{cccc}
\hline Proportion OBD in the classroom & $\begin{array}{c}\text { Overall } \\
\text { (percent) }\end{array}$ & $\begin{array}{c}\text { Between } \\
\text { (percent) }\end{array}$ & Within (percent) \\
\hline 0 percent & 2.04 & 5.64 & 46.49 \\
Between 0 and 50 percent & 24.33 & 41.23 & 51.65 \\
More than 50 percent less than 100 & 54.14 & 74.15 & 70.04 \\
100 percent & 19.48 & 46.75 & 51.66 \\
\hline
\end{tabular}

Appendix Table B3

Transition probabilities for the proportion OBD in classrooms

\begin{tabular}{ccccc}
\hline $\begin{array}{c}\text { Proportion OBD in the } \\
\text { classroom }\end{array}$ & 0 percent & $\begin{array}{c}\text { Between 0 } \\
\text { and 50 } \\
\text { percent }\end{array}$ & $\begin{array}{c}\text { More than 50 } \\
\text { percent less than } \\
\mathbf{1 0 0}\end{array}$ & 100 percent \\
\hline 0 percent & 37.24 & 52.71 & 8.8 & 1.25 \\
Between 0 and 50 percent & 3.44 & 62.58 & 29.25 & 4.72 \\
More than 50 percent less than 100 & 0.31 & 12.31 & 72.1 & 15.28 \\
100 percent & 0.27 & 12.37 & 52.15 & 35.21 \\
\hline
\end{tabular}

\section{APPENDIX B. Socio-economic Sorting and Variability in Actual Data}

The simulations of this paper are motivated by results obtained using real data from a large urban school district in the U.S. This section presents a description of the degree of socioeconomic sorting and variability between and within teachers in our observed data.

For this purpose we define a student to be classified as from observed background disadvantage (OBD status) if he is African American or Hispanic and receives free or reduced price lunch at school. With this information we then construct the proportion of OBD students in classrooms for each year. Table B1 summarizes the variability of this variable, overall, between teachers and within teachers over time. As we can see in this table there is more variation across teachers (between variation) than over time (within variation). In fact, 69 percent of the overall variance in proportion of OBD students in the classroom is due to variance between teachers while only 31 percent is due to variance within teachers over time.

Similarly, Table B2 offers additional details on the within and between variation for different ranges of values for the proportion of students with OBD status in classrooms. This table shows that most of the classrooms have between 50 and 100 percent of its students that are from disadvantaged backgrounds in our dataset. Around 26 percent of the classrooms have less than 50 percent of their students that are disadvantaged while 19 percent have all of its students that are disadvantaged. The between summary shows that 74 percent of the teachers have been ever assigned a class that has more than 50 percent disadvantage but less than 100 percent, while almost 48 percent have ever been assigned a classroom that is 100 
percent disadvantaged. On the other end only 6 percent of the teachers have ever been assigned a class that has no disadvantaged students at all. Finally the within summary indicates that 70 percent of the teachers who had a classroom with between 50 and 100 percent student that are disadvantaged always had this type of classroom. Similarly 52 percent of teachers who ever had a classroom with all students being disadvantaged and 52 percent of teachers who are ever observed with a classroom with between 0 and 50 percent proportions of disadvantaged students are always observed with that type of classrooms. Finally, 47 percent of teachers with classrooms with no disadvantaged students at all are always observed with these classrooms.

Table B3 presents transition probabilities from each category of the proportion of OBD students in the classrooms from one year to the next. This table shows that if a transition is observed to a different level of proportion of disadvantaged students it is often the case that the new level is and adjacent level.

Overall this descriptive analysis shows limited variability over time on the type of classrooms a teacher gets in terms of proportion of disadvantaged students. As a result, this may lead to considerable efficiency loss for estimators that rely on within variation only for its identification, such as teacher fixed effects estimators.

\section{APPENDIX C. Simulations Set-Up}

Our simulations datasets were created following the next steps:

1. We generated a dataset containing information on teacher effects and teacher identifiers for the 120 teachers considered in the simulations. The dataset is ordered in such a way that teachers with higher values of identifiers are of higher quality (i.e. have higher values of their teacher effects).

2. We generated a dataset containing school identifiers and 6 class identifiers per school for the 20 schools considered in the simulations. We then assigned values of proportion of students with OBD status randomly to schools in a way that we replicated the observed distribution in real data.

3. We generated a dataset at the student level containing information on the 2,400 students that we considered in our simulations. In particular we generated student identifiers and baseline test scores from a normal distribution with mean 0 and standard deviation 1, independently of student OBD status.

4. Students were then randomly assigned to schools and classes in year 1. Students were then assigned randomly a value for OBD status in such a way that we replicated the proportion of students with OBD status at the school they were assigned to.

5. For years 2 to 4 of data, students (keeping their assigned OBD status) are assigned randomly to classes within their assigned school.

6. Finally, we assigned teachers into schools either randomly (in the Random Assignment scenario) or depending on the proportion of OBD students in the 
school (in the partially systematic teacher assignment scenario). In the latter case, we ordered schools in terms of their values of proportion of students with OBD status and added values of random draws from a uniform distribution. Then teachers were assigned to schools such that those schools with higher values of the combined variable get the worse teachers in terms of lower permanent teacher effects. As a result schools with higher proportions of OBD students tent to receive lower quality teachers. The degree of this correlation is changed by increasing the standard deviation of the uniform distribution used to be added to the proportion of OBD students in schools and the subsequent ranking of schools. Teachers are then assigned to a class randomly within school. Teachers keep their assignment of school and class over the years. However, the students that are assigned to a teacher's class vary each year. 


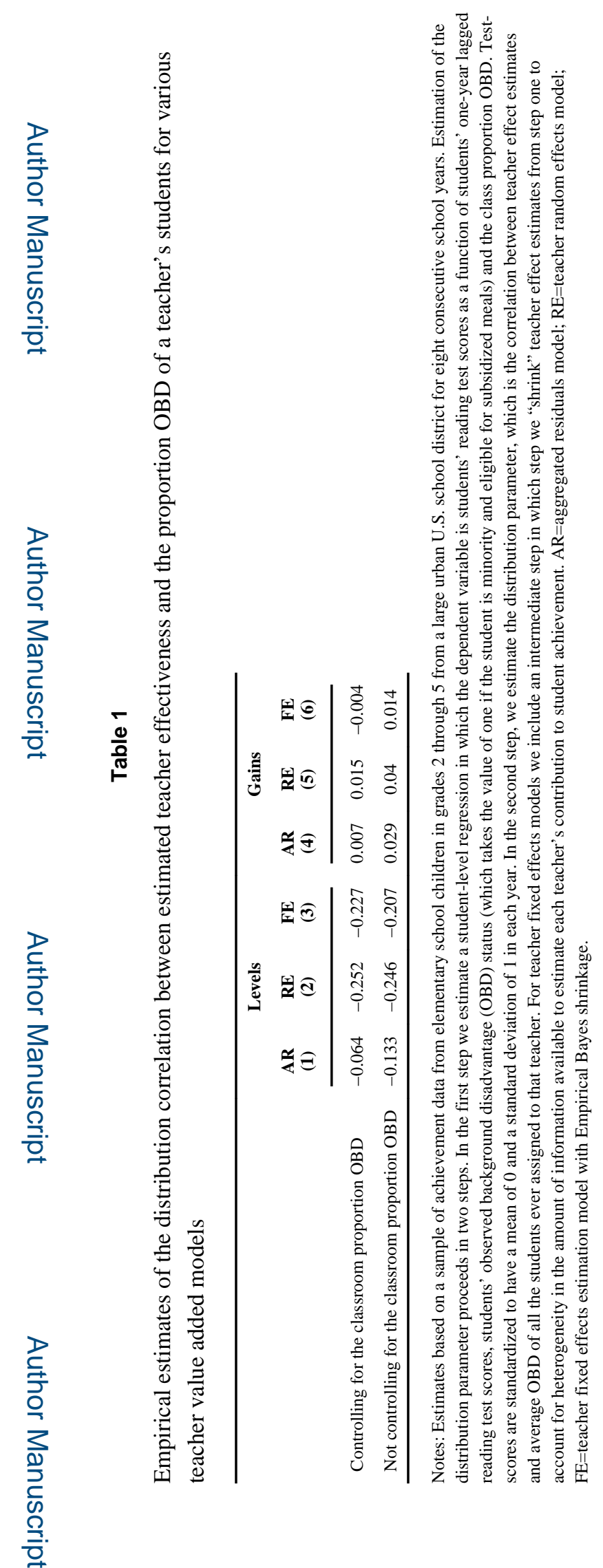

J Res Educ Eff. Author manuscript; available in PMC 2016 January 12. 


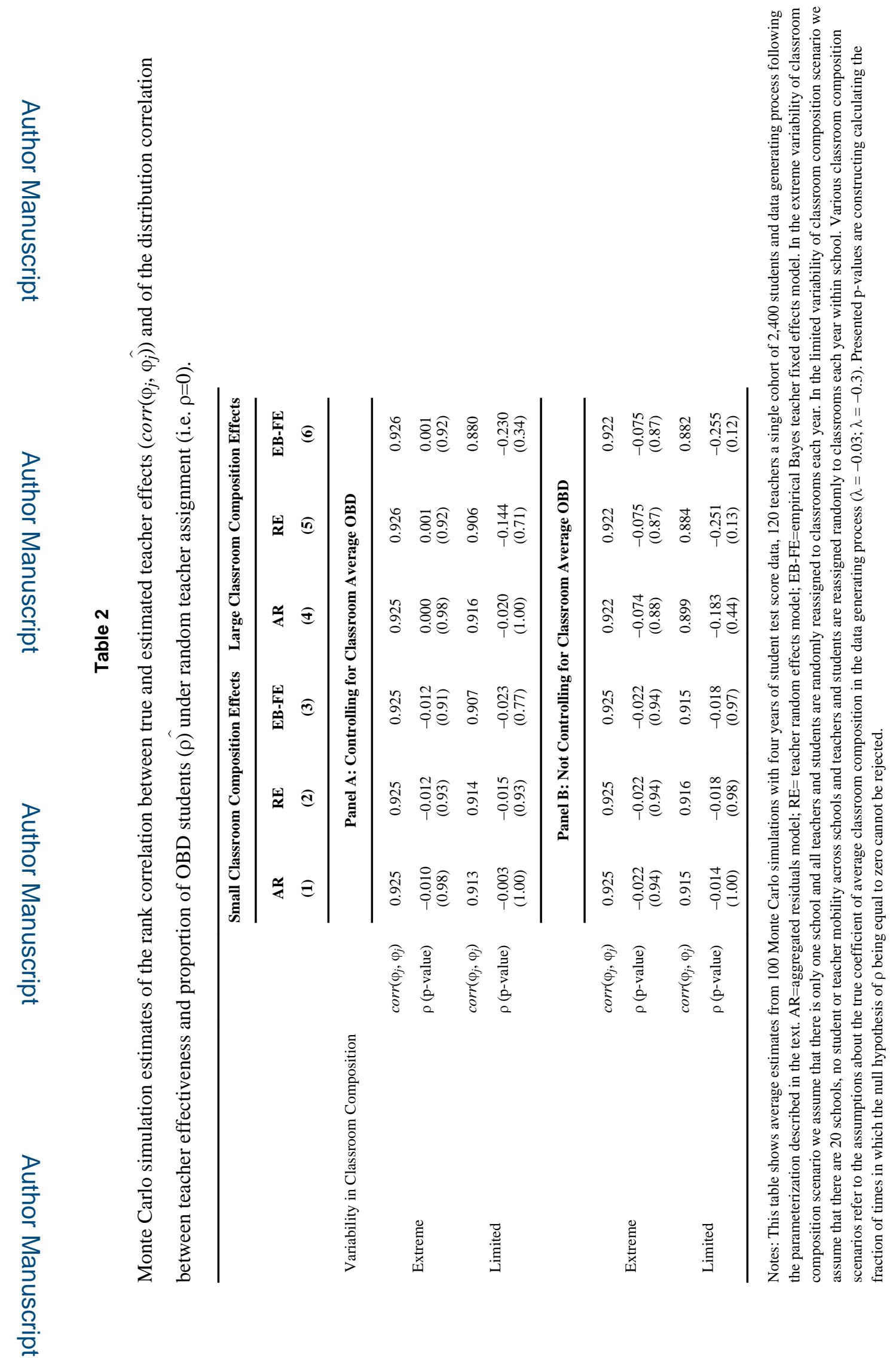

J Res Educ Eff. Author manuscript; available in PMC 2016 January 12. 


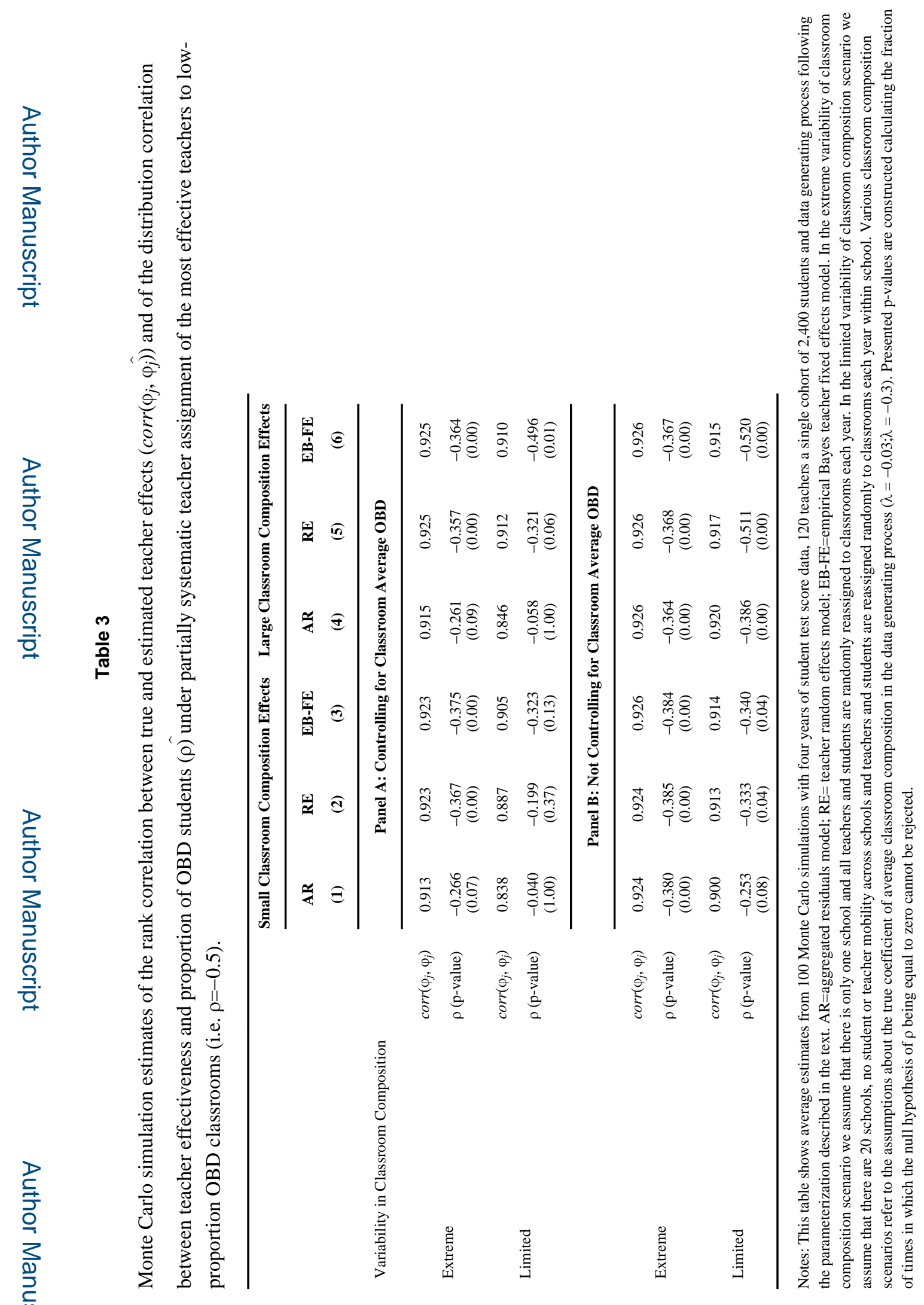

J Res Educ Eff. Author manuscript; available in PMC 2016 January 12. 


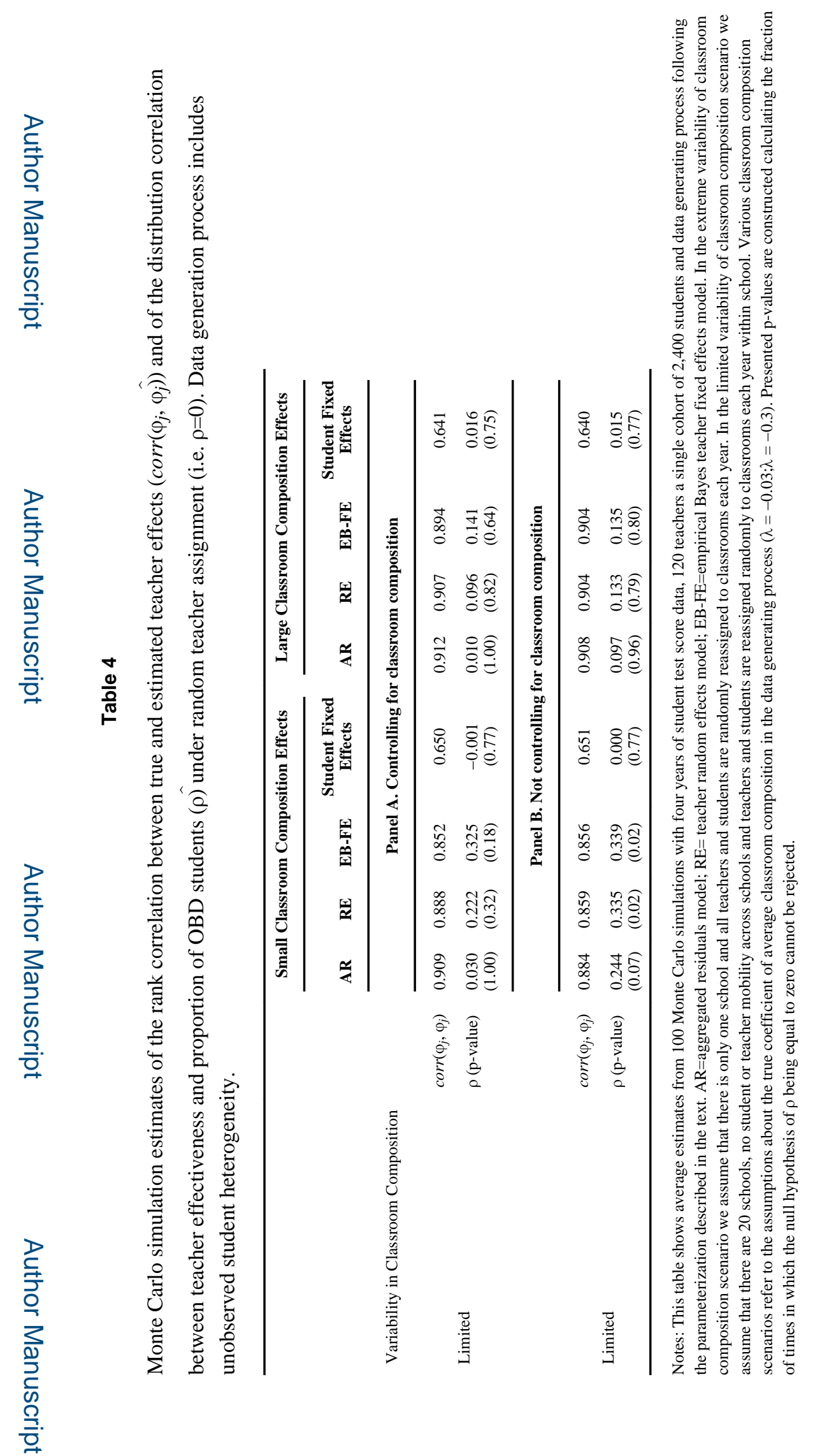

J Res Educ Eff. Author manuscript; available in PMC 2016 January 12. 


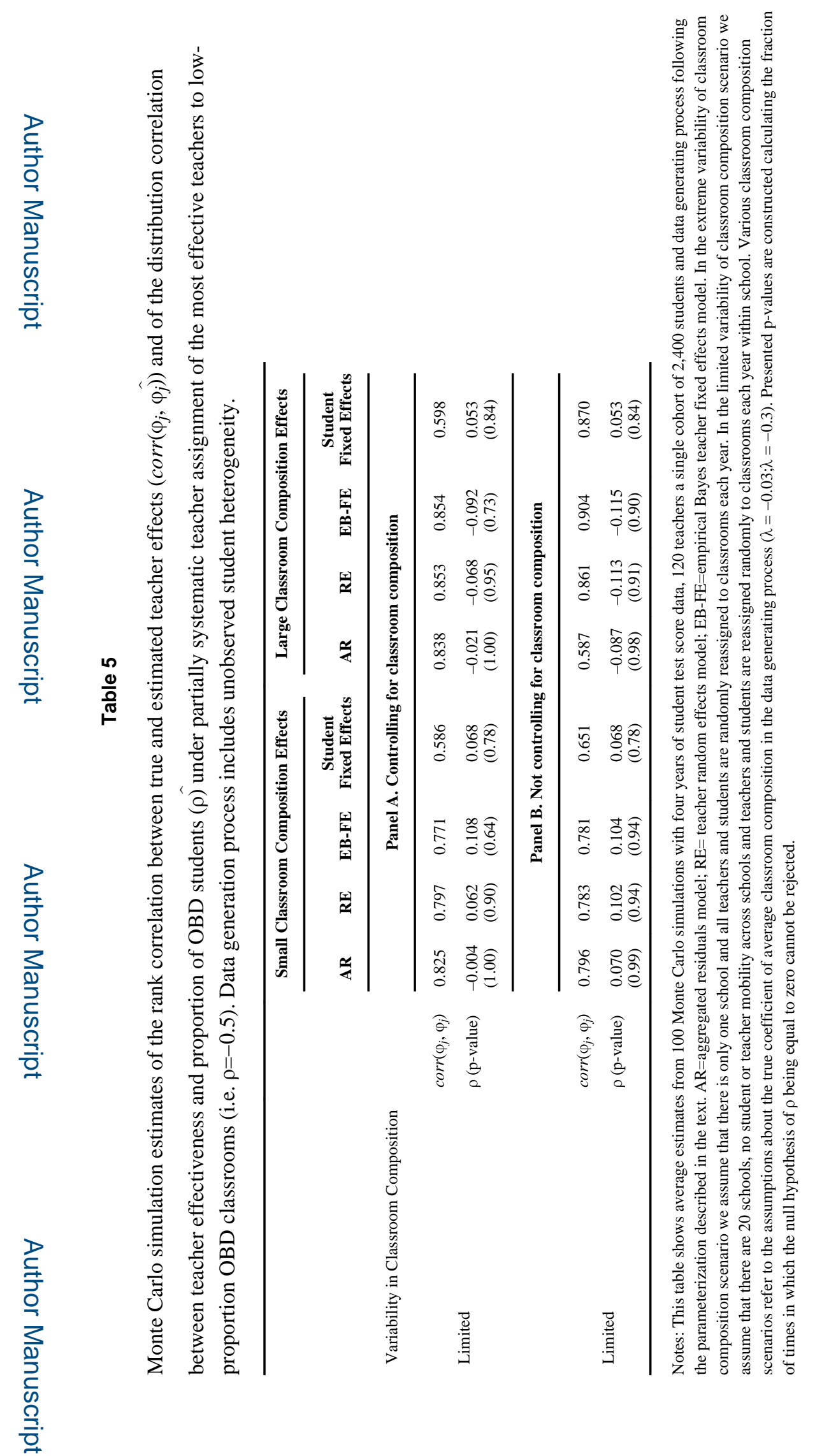

J Res Educ Eff. Author manuscript; available in PMC 2016 January 12. 